\title{
International and Asian Networks on Intense Laser Science
}

\author{
Yoshiaki Kato* \\ The Graduate School for the Creation of New Photonics Industries, 1955-1 Kurematsu, \\ Nishi-ku, Hamamatsu, Shizuoka, 431-1202 Japan
}

(Received January 2, 2009 : revised February 14, 2009 : accepted February 16, 2009)

\begin{abstract}
This paper reviews evolution of the research networks on intense laser science under international and Asian frameworks during 2000 to 2008. The OECD Global Science Forum Steering Committee on Compact, High-Intensity Short-Pulse Lasers led to the establishment of the International Union of Pure and Applied Physics (IUPAP) Working Group: International Committee on Ultrahigh Intensity Lasers (ICUIL) and the Asian Intense Laser Network (AILN) in 2004. Through various activities under AILN such as the Asian Symposium on Intense Laser Science (ASILS), the Asian Summer School on Laser Plasma Acceleration and Radiation, and the High-Order Harmonics Workshops, closer relations are being formed among the scientists and also among the young generations working in intense laser science in the Asian regions.
\end{abstract}

Keywords: Intense laser science, Ultrashort pulse lasers, High intensity lasers, OECD Global Science Forum, IUPAP, ICUIL, Asian Intense Laser Network, ASILS

OCIS codes : (000.1200) Announcements, awards, news, and organizational activities; (140.3580) Lasers, solid-state; (140.7090) Ultrafast lasers; (270.6620) Strong-field processes

\section{INTRODUCTION}

The Asian Intense Laser Network (AILN) was established in 2004 in order to promote collaboration on intense laser science and technology among research groups in Asian countries and regions [1], where there were limited occasions for scientific interaction in spite of geographical closeness and large populations in the Asian regions. On the occasion of the $4^{\text {th }}$ Asian Symposium on Intense Laser Science (ASILS4), I would like to review several activities that led to evolution of the international and Asian research networks in intense laser science, based on my personal involvements in these activities.

The invention of "chirped pulse amplification" (CPA) [2] has opened up a vast new range of exciting applications in science and technology by providing a new method to generate ultrahigh intensity and ultrashort optical pulses repetitively with compact lasers. In order to review the present status and future prospects brought by CPA, the OECD Global Science has organized a Workshop on Compact, High-Intensity Short-Pulse Lasers in 2002. Extending this activity, the IUPAP ICUIL (The Interna-

*Corresponding author: y.kato@gpi.ac.jp tional Committee on Ultra-High Intensity Lasers) was established for sustained actions on international coordination on ultrahigh intensity lasers and applications. AILN was established in 2004, in parallel with IUPAP ICUIL, to promote exchanges among the scientists in Asia. In this paper, after a brief survey of intense laser science in Asia and Japan, activities under OECD GSF, ICUIL, AILN and ASILS are reviewed.

\section{INTENSE LASER SCIENCE IN ASIA AND JAPAN}

Intense laser science is rapidly evolving in Europe, USA and in Asia. In Japan, very active researches covering various fields such as particle acceleration, coherent $\mathrm{x}$-ray generation, ultrafast intense laser science, and advanced laser development are being pursued at many organizations, including Osaka University, University of Electro-Communications, the University of Tokyo. Kyoto University, JAEA, RIKEN, CRIEPI and ETL. The active laboratories on intense laser science in Asia include; APRI, KAIST, KAERI and POSTECH in Korea, IOP, SIOM and CEAP in China, CAT and TIFR in India, 
and IAMS in Taiwan. The opening of the Quantum Beam Facility at the Advanced Photonics Research Institute, Gwangju Institute of Science and Technology in 2008 will make significant contributions to accelerating the research in intense laser science in Asia.

As to my personal account, I have engaged in high field science at the Institute of Laser Engineering (ILE), Osaka University and at the Advanced Photon Research Center (APRC), JAERI (now JAEA). At ILE, we have developed a 30-TW, 1-ps laser [3] in 1991 by applying $\mathrm{CPA}$ to a Nd:glass laser, the highest peak power from a single laser beam at that time. With this high intensity short laser pulse laser, creation of population inversions in short-wavelength x-ray laser media in recombining plasmas [4] and electron acceleration by self-modulated laser wake fields have been demonstrated for the first time [5]. Also we have constructed a new CPA beam line to the GEKKO-XII Nd:glass laser [6] in order to test the new concept of fast ignition of laser fusion proposed by Tabak [7]. This has lead to the observation of the fusion reactions due to heating of the compressed fusion fuel by high energy electrons under high intensity laser irradiation [8].

Based on the extensive study of future prospects of high field and ultrafast science opened by the TableTop TW lasers ( $\mathrm{T}^{3}$ lasers) [9], APRC was established in 1997 as a part of JAERI Kansai Research Establishment, which I joined in 1998. Intensive research was started at a new APRC facility in Kyoto Prefecture from 1999. A Ti-sapphire laser operating at $100 \mathrm{TW}, 20 \mathrm{fs}, 10$ $\mathrm{Hz}[10]$ and a 2-beam Nd:glass laser operating at $20 \mathrm{~J} /$ beam, 1 ps, 20 minutes shot period [11] were developed as the major drivers to investigate high field science with emphases on high energy electron acceleration and water -window x-ray lasers.

\section{OECD GLOBAL SCIENCE FORUM COMMITTEE ON COMPACT, HIGH-INTENSITY SHORT-PULSE LASERS}

In order to promote international cooperation on the development of high field and ultrafast science, Japan has submitted "A Proposal for a Workshop on International Cooperation in Ultrashort-Pulse, High-Power Lasers" to the OECD Global Science Forum (GSF) where science policy officials meet to identify and maximize opportunities for international cooperation in basic scientific research. This proposal, presented by the Japanese Delegate Yukio Sato (JAERI), was approved at the GSF Meeting in June 2000, and the "Steering Committee for the OECD Global Science Forum Workshop on Compact, High-Intensity Short-Pulse Lasers" was formed in order to prepare for the workshop. Organized by the Steering Committee, whose members are listed in Table 1, "The OECD Global Science Forum Workshop on Com-
TABLE 1. Members of the Steering Committee for the OECD Global Science Forum Workshop on Compact High-Intensity Shor $\exists$ t-Pulse Lasers (October 2000-January 2002)

\begin{tabular}{l|l|l}
\hline \hline Chair & Y. Kato & JAERI, Japan \\
\hline Vice-Chair & D. Hulin & LOA, France \\
\hline & T. Ditmire & LLNL, USA \\
\hline & H. Hutchinson & RAL, UK \\
\hline & S. Michalowski & OECD \\
\hline & G. Mourou & $\begin{array}{l}\text { CUOS, Univ. of Michigan, } \\
\text { USA }\end{array}$ \\
\hline & C. H. Nam & KAIST, Korea \\
\hline & W. Sandner & MBI, Germany \\
\hline & C.-G. Wahlstrom & Univ. Lund, Sweden \\
\hline
\end{tabular}

Note: Membership of the Coordinating Committee on Compact High-Intensity Short-Pulse Lasers (January 2002-January 2004) is composed of the above members with the change from T. Ditmire to C. P. J. Barty (LLNL, USA) and the new members S. L. Chin (Univ. Laval, Canada) and J. Zhang (Inst. Physics, China).

pact High-Intensity Short-Pulse Lasers: Future Directions and Applications" was held in May 28-30, 2001 at JAERI Kansai Research Establishment, Kyoto, Japan.

This workshop was attended by 56 government- appointed delegates comprising government officials, scientific experts and representatives of international organizations from 10 OECD member countries and 4 nonmember countries. This workshop covered broad range of subjects on high-intensity short-pulse lasers and their applications; atomic and molecular physics, biology, neutron science, nuclear physics, fusion energy research, high -field science, high-energy physics, x-ray imaging, cancer therapy and atmospheric science. The Final Report of the OECD Workshop (Fig. 1) [12] has given conclusions/recommendations for governments; (1) Systematic support is needed for laser development and applications and (2) Large-scale facilities offer advantages at the highest performance levels, and for the scientific community; (3) Coordination mechanisms in the community should be strengthened.

At the GSF Meeting in June 2001, this Workshop, as reported by Daniele Hulin, Vice-Chair of the Steering Committee, was evaluated to be highly successful, and it has been recognized that Research on Compact High -Intensity Short-Pulse Lasers is a field in its own right. As the framework for follow-up actions of the Workshop, especially to consider concrete ways of determining the coordination mechanism to strengthen the community for international cooperative activities, OECD GSF has approved the "Coordinating Committee on Compact, High -Intensity Short-Pulse Lasers” during 2002-2003 by slight- 


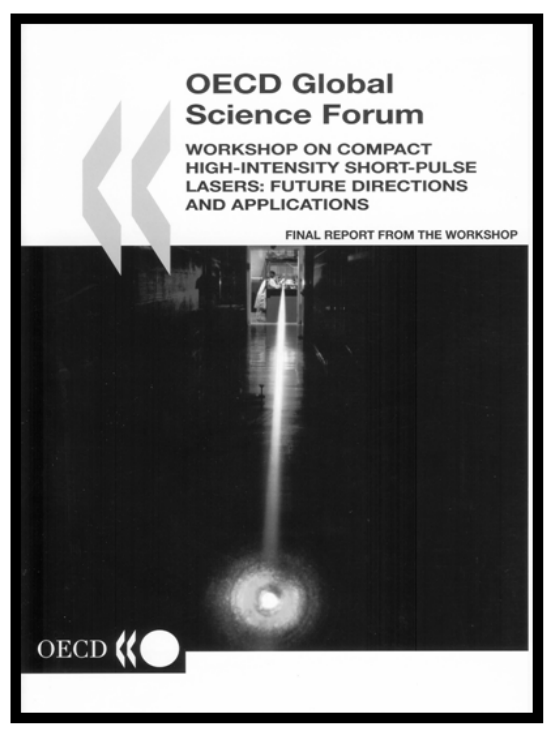

FIG. 1. Final Report, "OECD Global Science Forum Workshop on Compact High-Intensity Short-Pulse Lasers: Future Directions and Applications", OECD 2002.

ly expanding the membership of the Steering Committee (Table 1).

The Coordinating Committee has agreed to take the following actions;

- Identify the technological "bottlenecks" to enhanced performance of short-pulse lasers.

- Explore the prospects for a centralized conference focusing explicitly on compact high-intensity shortpulse lasers and their applications, so that it does not overlap with the existing conferences.

- Develop a set of technical standards and measurement procedures for the specifications and beam characteristics of various laser systems.

- Explore the possibility of establishing a "high-field optical science" category in relevant scientific journals.

- Encourage other activities to promote coordination, collaboration, trans-national access to facilities, education, training, and public outreach, as appropriate.

In accordance with the action items listed above, "The First Workshop on Technological Bottlenecks in Compact High-Intensity Short-Pulse Lasers" was held in Paris on April 1-4, 2003. This has turned out to be a very active workshop attended by 110 participants from 12 countries, $50 \%$ scientists and $50 \%$ from industry, reflecting strong needs for solving various bottlenecks in high performance Ti:sapphire lasers.

In order to establish a scientific body for these sustained actions, the Coordinating Committee has proposed to the International Union of Pure and Applied Physics (IUPAP) to form a Working Group under the aegis of IUPAP. The proposal to establish the IUPAP Working Group: International Committee on Ultrahigh Intensity Lasers (ICUIL) was presented by Wolfgang Sandner (MBI, Germany) at the IUPAP Executive Council in January
2003. After making several refinements for responding to the charges made by the Executive Council, the revised proposal, presented by Chris Barty (LLNL, USA), was approved at the IUPAP Executive Council Meeting in October 2003.

In total the OECD GSF Steering/Coordinating Committee on Compact, High-Intensity Short-Pulse Lasers met 7 times during October $2000 \sim$ September 2003. The final report on the activities of the Coordinating Committee with the major outcomes of the Workshop Report and the establishment of the IUPAP ICUIL, presented by Daniele Hulin, was well accepted at the GSF Meeting in February 2004.

It is encouraging that several projects to develop compact ultrahigh-intensity short-pulse lasers and research networks for efficient use of these facilities were started during these periods. These projects included LASERLAB Europe in EU, Advanced Laser Light Source in Canada, and PW Laser projects at APRI in Korea, although these were independent from GSF.

\section{IUPAP ICUIL}

The IUPAP ICUIL was established as an IUPAP Working Group with the sponsorships of the IUPAP Commissions C15 (Atomic and Molecular Physics), C16 (Plasma Physics, ICUIL Lead Commission) and C17 (Quantum Electronics). The activities of ICUIL are supported by these Commissions through the representatives of the Commissions as the members of ICUIL. In order to cover broader fields related to ultrahigh intensity lasers, the members of ICUIL are comprised of the Representative of IUPAP (A. Sen, Chair of C16), Representatives of High Intensity Laser Laboratories (10 members), Representatives of User Communities (6 members), and Representatives of FEL and the synchrotron radiation community (2 members). It was chaired by G. Mourou with the Co-Chairs of D. Hulin and T.Tajima. (New Board members were elected in 2008 with T. Tajima as the Chair, C. Barty and W. Sandner as the Co-Chairs and T. Kessler as the Secretary.)

The kick-off meeting of ICUIL was held on February 6-7, 2003 at the Rutherford Appleton Laboratory (Fig. 2). The IUPAP ICUIL was officially started on February 7, 2004 on which the first meeting of the ICUIL General Assembly approved the Charter of ICUIL. In accordance with the planning at the GSF Coordinating Committee, "The International Conference on Ultrahigh Intensity Lasers: Development, Science and Emerging Applications (ICUIL)" has been started and held every other year: ICUIL 2004 on October 3-7 in North Lake Tahoe, USA (Chair: C. P. J. Barty), ICUIL 2006 on September 25-29 in Cassis, France (Chair: G. Mourou), and ICUIL 2008 on October 27-31 in Shanghai, China (Chair: J. Zhang). It should be noted that the ICUIL confer 


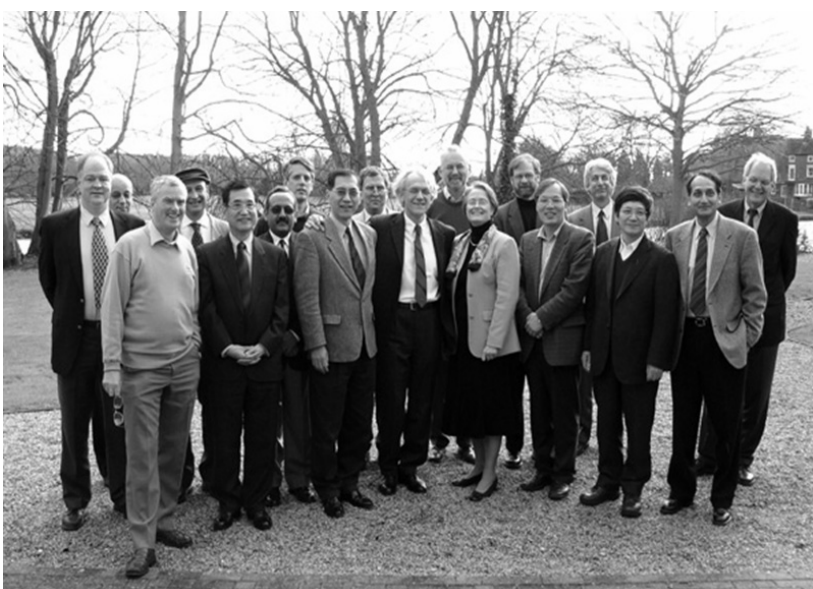

FIG. 2. The ICUIL Kick-off Meeting at the Rutherford Appleton Laboratory, UK in February 2004.

ences have focused on the ultrahigh intensity lasers and their emerging applications so that they do not overlap with other existing conferences such as high energy density physics, ultrafast science and short wavelength lasers.

\section{ASIAN INTENSE LASER NETWORK AND ASIAN SYMPOSIUM ON INTENSE LASER SCIENCE}

During preparation of IUPAP ICUIL at the GSF Coordinating Committee, which laid out the basic framework for the international collaborations, its Asian members have discussed promoting open exchanges among the scientists in Asia, since there had not been an appropriate forum in Asia for open exchanges in spite of rapid progress in high field science and recent economic growth in the Asian countries. Based on discussions among the leading scientists in Asia, it was decided to establish the Asian Intense Laser Network (AILN) in order to promote collaboration on intense laser science among the research groups in the Asian countries and regions.

AILN is intended to cover broad fields of "intense laser science" comprising ultrahigh- and high-field science, ultrafast atomic and molecular science, coherent shortwavelength radiation, short-pulse laser technologies, industrial applications, etc., rather than focusing on "ultrahigh intensity lasers". In this way AILN will be able to better serve to the broad interests of the scientists in Asia. As an organization AILN is operated independently from ICUIL.

The Asian Intense Laser Network has started its activities on June 18, 2004 with the kick-off meeting held during the First Asian Symposium on Intense Laser Science (ASILS1) at the University of Tokyo. The First Board Meeting was held on July 7, 2004 with the Board Members shown in Table 2, and the subsequent Board
TABLE 2. Board Members of the Asian Intense Laser Network (June 2004-July 2007)

\begin{tabular}{l|l|l}
\hline \hline Chair & Yoshiaki Kato & JAERI, Japan \\
\hline Co-Chair & Jongmin Lee & APRI, Korea \\
\hline Co-Chair & Jie Zhang & CAS IOP, China \\
\hline Co-Chair & Deepak Mathur & TIFR, India \\
\hline Co-Chair & Jyphing Wang & IAMS, Taipei \\
\hline Co-Chair & $\begin{array}{l}\text { Kaoru Yamanouchi } \\
\text { Univ. }\end{array}$ & Tokyo, Japan \\
\hline Secretary & Chang-Hee Nam & KAIST, Korea \\
\hline & Ruxin Li & SIOM, China \\
\hline Advisor & Soshiki Tajima & $\begin{array}{l}\text { JAERI Kansai Lab., } \\
\text { Japan }\end{array}$ \\
\hline
\end{tabular}

Meetings have been held during the ASILS conferences. (At ASILS3 in 2007, the AILN Board has elected J. Lee as the new Chair and $\mathrm{R}$. $\mathrm{Li}$ as the new Secretary with addition of a few new Board Members, in order to run AILN under the responsibilities of various countries and to reflect the steady expansion of the AILN activities.)

The Asian Symposium on Intense Laser Science (ASILS) has been established as an important forum for exchanges on scientific advances among the scientists in Asia. It has been held almost every year: ASILS1 in Tokyo, Japan on June 17-19, 2004 (Chair: K. Yamanouchi), ASILS2 in Kochi, India on January 22-27, 2006 (Chair: D. Mathur), ASILS3 in Cameron Highland, Malaysia, on July 2-5, 2007 (Chair: T.-Y. Tou), and ASILS4 in Gwangju, Korea on November 3-6, 2008 (Chair: J. Lee). Each ASILS has been very successful, rich in science and also in culture, owing to the hospitable arrangements by the Local Organizing Committees. As was shown at ASILS3, in which many scientists in the South -East Asia have participated (from Malaysia, Singapore, Indonesia, Vietnam and Philippine), interaction with the scientists in various regions in Asia is an important direction that ASILS can take, since the interaction will contribute to stimulating science in the regions where the laser science community is not yet well established.

There are also other important activities organized by AILN. One is The Asian Summer School on Laser Plasma Acceleration and Radiation. This Summer School has been held in every year: the $1^{\text {st }}$ at IOP, Beijing, China on August 7-11, 2006 (Chair: Z. Sheng), the $2^{\text {nd }}$ at JAEA Kansai, Kyoto, Japan on August 6-10, 2007 (Chair: T. Tajima), the $3^{\text {rd }}$ at APRI, Gwangju, Korea on July 21-25, 2008 (Chair: J. Lee) and the $4^{\text {th }}$ planned in Taiwan in 2009 (Chair: Y.-C. Huang).

Another is The Asian Workshop on Generation and Applications of High Order Harmonics organized by The 


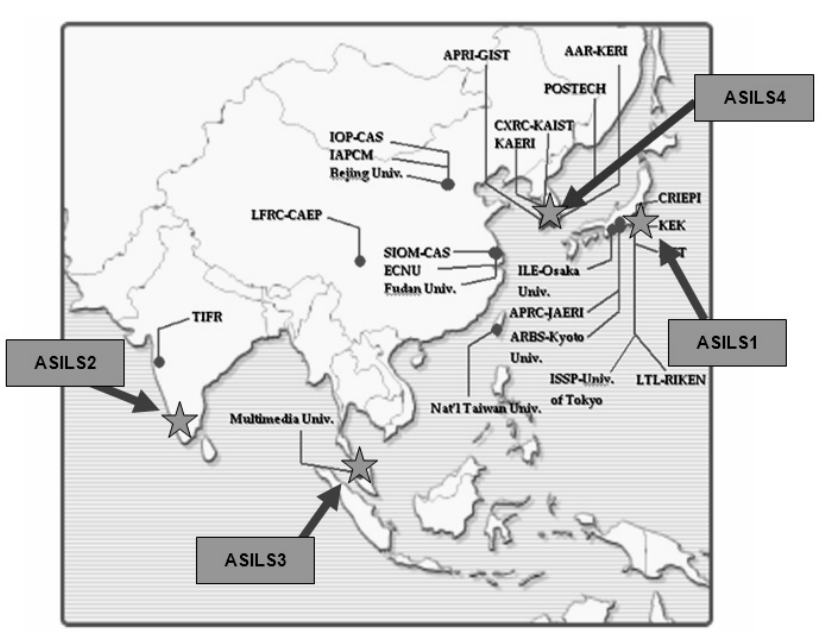

FIG. 3. ASILS1 4 have been held in Japan, India, Malaysia and Korea, respectively.
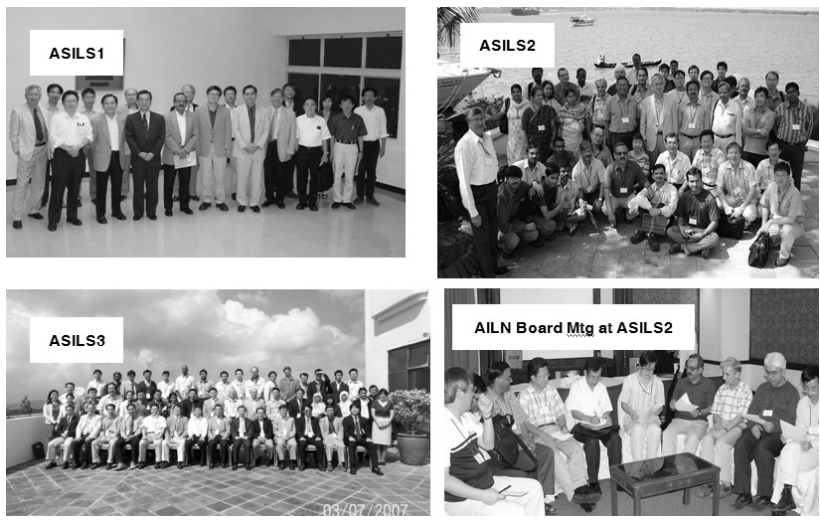

FIG. 4. The participants at ASILS1 3 and the AILN Board Meeting at ASILS2.

Asian Coherent X-Ray Network, which is a Panel (subgroup) of AILN, lead by C. H. Nam (KAIST, Korea), K. Midorikawa (RIKEN, Japan) and R. Li (SIOM, China). This Workshop has been held in every2 years; the $1^{\text {st }}$ at KAIST, Korea on February 23-25, 2005, the $2^{\text {nd }}$ at RIKEN, Japan on May 30-June 1, 2007 and the $3^{\text {rd }}$ planned at Wuhan, China in 2009.

These AILN activities have been held with the supports of the organizing and participating institutes, and also of the Governmental programs for Asian collaboration; Trilateral (Korea-Japan-China) Collaboration on Ultra-Short High Intensity Laser and Its Applications (2005-present, Co-chairs: J. Lee, T. Tajima and J. Zhang) and JSPS Asian CORE Program on Development of Next Generation Ultra-Short Pulse Lasers for High Field Science (2007-2011, Chair: K. Ueda, Co-chairs: J. Zhang, C. H. Nam, D. Mathur). Under the Trilateral Collaboration program, several joint experiments were undertaken on particle acceleration where Japanese scientists stayed at the laboratories in Korea or China for extended periods and vice versa.

\section{CONCLUSION}

It is very encouraging that close friendships are being formed among the scientists and also among the young generation working in the field of intense laser science in the Asian regions, since the scientists and young researchers have met each other and/or worked together many times in these several years through ASILS, Asian Summer School, Asian Workshop on High Order Harmonics and other related activities. It is hoped that these activities will contribute to advancing the frontiers in intense laser science and also to strengthening its research bases in Asia as well as in the worldwide community.

\section{ACKNOWLEDGMENT}

I would like to thank all with whom I have worked together at the OECD Global Science Forum Steering/ Coordinating Committee on Compact, High-Intensity Short-Pulse Lasers, IUPAP ICUIL, Asian Intense Laser Network, ASILS and other related activities, for invaluable experiences I had in these several years. Especially I would like to thank Prof. Chang-Hee Nam for his cooperation throughout these activities.

\section{REFERENCES}

1. Charter of The Asian Intense Laser Network, http:// apri.gist.ac.kr/ailn/index.php

2. D. Strickland and G. Mourou, "Compression of amplified chirped optical pulses,” Opt. Commun. 56, 219-221 (1985).

3. K. Yamakawa, C. P. J. Barty, H. Shiraga, and Y. Kato, "Generation of a high-energy picosecond laser pulse with a high-contrast ratio by chirped-pulse amplification,” IEEE J. Quant. Electron. 27, 288-294 (1991).

4. H. Azuma, Y. Kato, K. Yamakawa, T. Tachi, M. Nishio, H. Shiraga, S. Nakai, S. A. Ramsden, G. J. Pert, and S. J. Rose, "Short-pulse pumping of a recombination Balmer-a laser of hydrogenic sodium,” Opt. Lett. 15, 1011 -1013 (1990).

5. K. Nakajima, D. Fisher, T. Kawakubo, H. Nakanishi, A. Ogata, Y. Kato, Y. Kitagawa, R. Kodama, K. Mima, H. Shiraga, K. Suzuki, K. Yamakawa, T. Zhang, Y. Sakawa, T. Shoji, Y. Nishida, N. Yugami, M. Downer, and T. Tajima, "Observation of ultrahigh gradient electron acceleration by a self-modulated intense short laser pulse," Phys. Rev. Lett. 74, 4428-4431 (1995).

6. Y. Kato, Y. Kitagawa, R. Kodama, H. Takabe, H. Fujita, T. Jitsuno, T. Kanabe, M. Nakatsuka, K. A. Tanaka, H. Shiaga, K. Sawai, S. Miyamoto, M. Honda, S. Nakai, K. Mima, H. Sakagami, and C. Yamanaka, "Approaches to fast ignition in inertial confinement fusion at ILE, Osaka," in Proc. 16th IAEA Fusion Energy Conference (Montreal, Canada, 1996), paper IAEA-CN-64/B2-6.

7. M. Tabak, J. Hammer, M. E. Glinsky, W. L. Kruer, 
S. C. Wilks, J. Woodworth, E. M. Campbell, M. D. Perry, and R. J. Mason, "Ignition and high gain with ultrapowerful lasers,” Phys. Plasmas 1, 1626-1634 (1994).

8. R. Kodama and the Fast-Ignitor Consortium, "Fast heating scalable to laser fusion ignition," Nature 418, 933-934 (2002).

9. H. Takuma, ed., Birth and Future Prospect of Advanced Photon Science (Science and Technology Agency, Japan, October 1996).

10. K. Yamakawa, M. Aoyama, S. Matsuoka, T. Kase, Y.
Akahane, and H. Takuma, "100-TW, sub-20-fs Ti:sapphire laser system operating at a $10 \mathrm{~Hz}$ repetition rate," Opt. Lett. 23, 1468-1470 (1998).

11. T. Kawachi, M. Kado, M. Tanaka, N. Hasegawa, K. Nagashima, K. Sukegawa, P. Lu, K. Takahashi, S. Namba, M. Koike, A. Nagashima, and Y. Kato, "Development of a pumping system for x-ray laser research," Appl. Opt. 42, 2198-2205 (2003).

12. Final Report, "OECD global science forum workshop on compact high-intensity short-pulse lasers: future directions and applications," OECD 2002. 